\title{
SERTÕES DE CANINDÉ: UMA INTERPRETAÇÃO GEOSSIMBÓLICA DA PAISAGEM
}

- OTÁVIO JOSÉ LEMOS COSTA'

\begin{abstract}
RESUMO

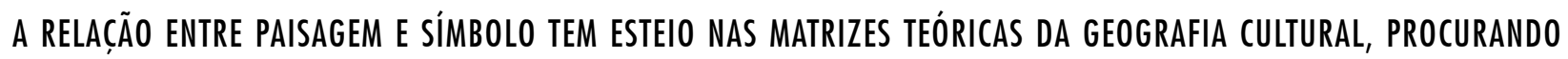
EXPLICAR A EXISTÊNCIA DE UM CONJUNTO DE SIGNOS QUE ESTRUTURAM A PAISAGEM. 0 OBJETIVO DESTE TEXTO É FAZER

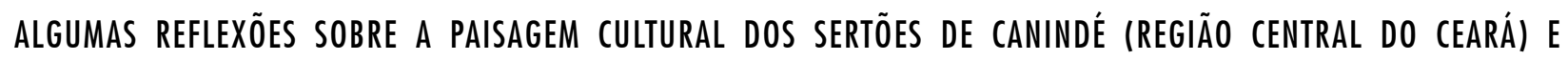
ENTENDER O SEU ASPECTO SIMBÓLICO. CONTEXTUALIZANDO ESTA PAISAGEM NA PERSPECTIVA DO SAGRADO, IDENTIFICAMOS DOIS ELEMENTOS QUE A CARACTERIZAM: A ROMARIA E OS MARCOS OBITUÁRIOS AO LONGO DA ESTRADA DE CANINDÉ. ASSIM, PROCURAMOS IDENTIFICAR OS PRINCIPAIS ELEMENTOS GEOSIMBÓLICOS, ENTENDENDO QUE A PRESENTE PAISAGEM EXPRESSA UMA DADA CULTURA E REALIZA SEU PAPEL DE tRANSFORMAC̦ÃO CULTURAL REPRESENTADA NAS FORMAS SIMBÓLICAS QUE ORIGINAM SIGNIFICADOS PLURAIS.
\end{abstract}

PALAVRAS-CHAVES: GEOSÍMBOLO - PAISAGEM- SAGRADO - SERTÃO

Entre as mais diversas categorias de análise que constituem o escopo teórico-metodológico da geografia, a paisagem é aquela que mais evoca relações com o sujeito. Os elementos simbólicos presentes em cada paisagem comportam um conjunto de valores que foram atribuídos subjetivamente por aqueles que fazem parte de seu entorno. Consoante ao pensamento de Bonnemaison (2000), verificamos que a presença de marcos geossimbólicos confere ao lugar um sentido, uma ética e também uma espiritualidade. Assim, uma paisagem cultural reúne um conjunto de representações que engendram uma rede de significados, produzindo a cada momento valores que se articulam na construção de novas paisagens simbólicas.
Embora o conceito de paisagem não seja exclusivo da geografia, tradicionalmente ele foi incorporado as suas discussões, procurando definir, organizar e sugerir uma concretude ao espaço. No âmbito da geografia, procuramos entender a relação entre paisagem e símbolo trilhando a perspectiva da Geografia Cultural. Neste contexto, a paisagem faz parte da realização humana, eivada de um significado pleno no seu sentido fenomenológico, marcada pelas ações e interelações coletivas dos grupos humanos que através da mediação simbólica irão modificar continuamente o seu entorno

Nesse processo interativo entre o homem e a paisagem, sugere Cosgrove (2000) que o elemen- 
to da comunicação seja o alicerce forjado de uma intersubjetividade, onde os valores e crenças compartilhados constituem a imaginação coletiva e definidora da cultura não-material. A paisagem permanece, no dizer de Cosgrove e Jackson (1987), um terreno fértil para os geógrafos culturais. Ao reconstruir os conceitos de paisagem e de cultura com novas referências conceituais, os estudos da geografia cultural irão enfatizar o caráter de construção cultural, estabelecido a partir da própria definição de paisagem.

Para os teóricos da Escola de Berkeley, o conceito de paisagem é, ele próprio, um modo especial de compor estruturas e dar significado a um mundo externo, cuja história tem que ser entendida em relação à apropriação material da natureza. Dessa forma, os aspectos simbólicos da paisagem que produzem e sustentam o significado dos lugares, tornam-se objetos de pesquisa ampliando as fontes disponíveis para a geografia cultural.

A relação entre paisagem e símbolo tem esteio nas matrizes teóricas da geografia cultural, procurando explicar a existência de um conjunto de signos que estruturam a paisagem. Nesse direcionamento, buscamos no presente texto, fazer algumas reflexões sobre a paisagem cultural dos Sertões de Canindé (região central do Ceará), objetivando entender o seu caráter simbólico. Se todas as paisagens formatam um significado simbólico (RAPOPORT, 1982), procuramos aqui identificar os principais elementos geossimbólicos presentes naquela paisagem, convergindo para uma proposição metodológica onde a análise interpretativa seja mais relevante que a morfológica, onde os múltiplos significados da paisagem ensejam uma decodificação. Pretende-se ainda realizar o enten- dimento dos diversos elementos simbólicos presentes em um trecho do semi-árido cearense, entendendo que a paisagem aí construída expressa uma dada cultura e realiza seu papel de transformação cultural representada nas formas simbólicas que originam significados plurais.

Enquanto exercício metodológico, definimos um suporte teórico para compreender a interação entre a paisagem e seu caráter simbólico. Privilegiamos a análise do real que foi construída através da prospecção imagética de determinados elementos típicos do lugar e que passam a ter interesse ampliado como referência de identidade e ao mesmo tempo adquire um valor simbólico. $\mathrm{O}$ entendimento do vernáculo da paisagem atesta também a relação que o sujeito mantém com o lugar. expressando a sua formação e continuidade, mantidas com o propósito de revelar uma imagem e que, segundo Bachelard (1993), não precisa necessariamente está ligada a um passado longínquo. Portanto, compreender os Sertões de Canindé a partir de valores, sejam eles morais, religiosos, éticos, etc., que estruturam uma simbiose entre o homem sertanejo e seu espaço vivido, é também olhar esse cenário como imagem singular cujos significados tecem uma estrutura espacial simbólica.

Encravado na ampla depressão sertaneja, o sertão de Canindé, apresenta uma paisagem plena de significados simbólicos, representados tanto por seus elementos naturais - aqui definidos pelo caráter de extrema aridez - como também pelos ícones representativos de uma paisagem cultural $\mathrm{cu}$ jos significados são passíveis de uma interpretação. Nossa discussão estará centrada na compreensão dos elementos geossimbólicos associados à natureza de um espaço sagrado bem representati- 
vo na área em tela como também o caráter simbólico daquela paisagem enquanto produto e matriz cultural.

Para o entendimento dos elementos geossimbólicos da paisagem em nosso objeto de análise, faremos uma breve discussão sobre a categoria paisagem, entretanto mais direcionada à relação espaço-símbolo, uma vez que é ampla a literatura sobre a discussão do conceito de paisagem. A definição de paisagem, assim como muitas outras que utilizam os geógrafos, é longamente utilizadas no senso comum e em outras ciências. Para Bomer (1994), o encontro com a paisagem está associado a uma descrição explicativa da superfície terrestre. Entretanto, é sabido que o estudo da paisagem na ótica de uma geografia humanista reduz essa abrangência espacial e foca sua análise para os aspectos subjetivos. Dessa maneira, a análise da paisagem deve ser feita com a contribuição de outras ciências humanas tais como a antropologia, a sociologia, a história, etc. A esse respeito, Bomer (1994) argumenta que as relações estabelecidas entre a paisagem e o sujeito, permite ao geógrafo tentar objetivar a análise dos elementos que contenham uma natureza subjetiva.

Em relação ao simbólico presente na paisagem, Corrêa (1997) citando Isnard, afirma que o espaço geográfico é também um campo de representações simbólicas, rico em signos que cumprem a função de expressarem estruturas em suas múltiplas dimensões. Essas representações simbólicas revestem-se de um poder que gera um interacionismo entre as formas espaciais e o sujeito, muitas vezes engendrando instrumentos de dominação e que, na visão de Bourdieu (1990), representam sistemas simbólicos quase sempre imbuídos de ideo- logias que servem interesses particulares no quais se revestem como interesses universais. Assim, a cultura dominante contribui para a formação de uma paisagem de cultura dominante tão bem explicitada por Cosgrove (1998), quando argumenta que, em termos de paisagens existentes, naturalmente somos inclinados a ver a expressão mais clara da cultura dominante no centro geográfico do poder.

Esse simbolismo que permeia a paisagem é organizado, conforme Bourdieu (1990), como um poder estruturado. A construção do real está imbricada com o poder simbólico que tende a estabelecer uma ordem, um sentido de mundo provocando uma lógica interacionaista ou um caráter solidário. O simbolismo da paisagem é, portanto, uma característica fundamental para se compreender a interação existente entre o homem e o seu entorno, servindo ao propósito de estabelecer normas culturais e os valores de um determinado grupo. Portanto, a compreensão dos elementos geossimbólicos, é uma condição necessária para a compreensão de uma paisagem cultural, não sendo possível sem a consideração dos sistemas simbólicos ali atuantes, uma vez que os símbolos refletem a estrutura da paisagem onde as imagens, os arquétipos são diversamente vividos e valorizados, sendo assim, o produto de suas várias atualizações e que constituem estilos culturais (ELIADE, 1991).

A importância do símbolo na paisagem e suas adaptações configuram um sistema de significações. A esse respeito, Silva (1993) nos chama atenção para a importância em interpretar os símbolos que garantem os modos de vida e a relação entre os indivíduos ou grupo de indivíduos com seu 
ambiente. Essa estreita relação entre o homem e seu mundo vivido tem sido o foco da análise dos fenomenologistas, que elegem a experiência social e a interação direcionadas mais para as relações interpessoais que as intergrupais. Buttimer (1985) argumenta que descrevendo a experiência humana do "mundo", do espaço e do tempo, também existe a tendência para enfatizar os sujeitos humanos como os iniciadores primários e determinantes da experiência.

$\mathrm{Na}$ tentativa de identificar as relações entre símbolo e paisagem, argumenta Monet (1991) que os símbolos mediatizam as relações entre espaço, poder e identidade, onde o símbolo é uma realidade material que comunica algo imaterial. Assim, verifica-se que a paisagem é plena de significados, sua forma se expressa em termos simbólicos determinados pelas circunstâncias históricas que a produz. A discussão entre símbolo e paisagem também é considerada na análise que Holzer (2001) apresenta sobre o pensamento de Eric Dardel, ancorado na abordagem fenomenológica desse autor, argumenta que a paisagem enquanto categoria espacial multifacetada deve ser considerada em seu conjunto, ou seja, uma convergência, um momento vivido, uma ligação interna, uma impressão que une todos os elementos.

$\mathrm{Na}$ perspectiva da análise etnogeográfica da paisagem, podemos perceber que os símbolos conformam uma percepção de mundo. Geertz (1989) nos mostra que no âmago desse debate se encontram os aspectos morais e estéticos de uma dada cultura bem como os elementos valorativos que irá conceituar como "ethos". Por outro lado, nos chama atenção para os aspectos cognitivos existenciais que serão designados de "visão de mun- do". Consoante ao pensamento de Geertz (1989), entendemos que a "visão de mundo" atrela-se à dimensão etnográfica da paisagem, uma vez que possibilita uma relação significativa entre os valores que as pessoas conservam e a ordem geral de uma existência. Nesse direcionamento, Claval (1999) irá enfatizar as razões do interesse por essa temática mostrando que o espaço que vivenciamos e observamos é moldado pela ação dos homens e se encontra marcado por seus saberes, seus desejos e suas aspirações. A etnogeografia possibilita, portanto, compreender como os homens produzem e modificam a paisagem a partir da percepção, da imagem que eles têm dessa paisagem. Nos mostra Claval (2001) que muitas vezes a geografia humana negligencia a dimensão simbólica, enfatizando as lógicas econômicas na interpretação dos espaços humanizados. Para este autor, os homens não podem viver sem dar um sentido àquilo que os cerca. Sua preocupação não reside somente em satisfazer as suas necessidades e assegurar a transmissão do que sabem às futuras gerações.

\section{A EXPRESSÃO SIMBÓLICA DA PAISAGEM SERTANEJA}

A construção da paisagem do sertão nordestino aparece no imaginário social como um sistema de significados, se apresentando como expressão da rudeza, do não civilizado, dos arquétipos tradicionais onde os movimentos de resistência aos processos de mudança mantêm sólidas estruturas de poder. Entretanto, existe uma dialética nesse processo que apresentam um espaço de autenticidade, do racionalismo que remete aos traços mais puros de uma paisagem-pátria. Ocorre assim, a resposta ao poder construído pela pujança e dominação do litoral, que foi organizado como antítese 
ao litoral, com o simbolismo do interior da semiaridez, do horizonte a perder de vista, enfim um todo genérico e uniforme. Esse dimensionamento da paisagem sertaneja está explicito na obra de José de Alencar, O Sertanejo, quando expressa com firmeza o sertão cearense na seguinte passagem: Esta campina, que se dilata por horizontes infindos, é o sertão da minha terra natal. Aí campeia o destemido vaqueiro cearense, que a unha do cavalo acossa o touro indômito no cerrado mais espesso, e o derruba pela cauda com admirável destreza.

È possível reconhecer no "Sertanejo" de Alencar a íntima relação que a paisagem estabelece com o homem. Além dessa perfeita harmonia com o meio, existe também o compartilhamento com outros seres da natureza, seus elementos de reprodução da vida, fazendo com que haja uma interação com os mesmos. O homem sertanejo se comunica com os animais, com as plantas, com o solo, interpreta os aspectos naturais percebendo através do ambiente, sinais quase imperceptíveis da natureza. Essa forte simbiose faz com que o sertanejo se considere um ente fruto daquele ambiente, como a árvore da caatinga ou as aves de arribação que compõem seu espaço vivido.

A paisagem sertaneja no Nordeste brasileiro nos remete a uma realidade plena de significados simbólicos e que foram sendo construídos historicamente. A esse processo de construção do sertão, são incorporados outros elementos tais como: a seca, a miséria e a religiosidade. Souza (1997), nos explica que o sertão ganha descrição no pensamento social que o caracteriza como lugar de reprodução de uma ordem social específica. Assim, a existência de uma sociedade sertaneja pode ser entendida a partir dos contrastes entre os modos de vida litorâneo e mediterrâneo, onde o anúncio da diferença reflete o sentimento de distanciamento entre aqueles que vivem o sertão e os "de fora". Almeida (2003) nos chama atenção para a construção discursiva sobre o sertão, onde o olhar, a maneira como ele é pensado, reflete a maneira de ver o mundo.

As representações sócioambientais resultam, portanto, no ato de observar, de contemplar a natureza. Argumenta Meinig (1979) que um simples exercício do olhar sobre a paisagem, a partir de um variado grupo, nos permite múltiplos significados dessa paisagem. É a partir dessa relação entre a paisagem e representações simbólicas que fazemos uma interpretação sobre os elementos geossimbólicos da paisagem sertaneja, onde as representações calcadas na aparência da paisagem se vinculam às práticas discursivas também produtoras da realidade. O conjunto de sentidos e significados que formatam a paisagem do sertão é o produto de uma teia de imagens, conceitos e idéias que vão construindo um conjunto de signos e delimitando fronteiras (FERREIRA e DANTAS, 2001).

Talvez a imagem simbólica mais defendida sobre a paisagem do sertão nordestino seja a seca. Pordeus Jùnior (2003) nos apresenta essa imagem representada na visão de alguns autores cearenses como Oliveira Paiva, Rodolfo Theófilo e Patativa do Assaré, que narram a miséria produzida pela seca e seu imediato reflexo. O retirante é bem representado por Patativa do Assaré quando diz em seus versos "Eu vendo meu burro, meu jegue e o cavalo, nós vamo a São Paulo vive ou morre (...) oiando pra terra, sem berço, sem lar, aquele nortista, partindo de pena ainda acena, adeus Ceará". 
As representações sociais voltadas para as imagens do sertão, tendo como tema central o território das secas, converge para um sistema de representações construídas. Segundo Castro (1992), a vegetação da caatinga ressequida irá projetar a imagem da região onde a seca ofuscava os problemas sociais, permanecendo também como uma fronteira entre a civilização e o progresso. Como observa Hoefle (1996), o quadro de semi-aridez associado ao subdesenvolvimento econômico e social colocou o sertão nordestino até 1930 em uma zona de fronteira caracterizado por uma rarefação demográfica, um baixo grau de capitalização das atividades econômicas e virtual ausência de controle do governo central.

\section{INTERPRETANDO O SIMBÓLICO NOS SERTÕES DE CANINDÉ}

Compreender os Sertões de Canindé, sua paisagem, seus habitantes, tudo do que dele faz parte, dentro de um amplo sentido de identificação com os elementos simbólicos, é tentar conjugar uma associação de idéias gerais que opera no sentido de fazer com que o símbolo seja interpretado. É buscar nos seus elementos geossimbólicos a natureza dos ícones mais representativos e que, na visão de Peirce (1990), deve ser particularizado naqueles elementos que o tornam significante por uma característica que reside no fato que será interpretada com o símbolo.

A paisagem dos Sertões de Canindé guarda a existência de um complexo universo simbólico. Esse sentimento de identificação com o lugar reforça a idéia de que a paisagem aí representada não é apenas a conjunção de elementos naturais ou culturais justapostos numa lógica sócioespacial mas algo que produz significados, ou seja, um sis- tema de representação cultural. Aqui os indivíduos, sejam aqueles que vivem nesse sertão ou então aqueles que transitam nas romarias à Canindé, participam dessa paisagem produzindo, dialogando, estabelecendo assim um reuso da identidade, engendrando espacialidades do formas simbólicas e, como sugere Gil Filho (2005), são espacialidades ou morfologias simbólicas dos objetos espaciais que irão configurar como a dimensão da paisagem.

Contextualizando os Sertões de Canindé, na perspectiva das estruturas do sagrado, identificamos em nossa análise dois elementos que caracterizam a paisagem: a romaria e a presença de cruzes e marcos obituários ao longo das estradas. A romaria, considerada como uma constante expressão peculiar às mais variadas tradições religiosas, é objeto de análise de estudiosos da religião sobre o ato de caminhar e suas representação perante as estruturas do sagrado (SILVA, 2003). A romaria, portanto enquadra-se como a busca de um objetivo e nessa busca expressa-se a noção de experiência da espacialidade que se manifesta através da relação do sujeito com o mundo, em um contexto que determina um campo perceptivo com seu espaço vivido.

A busca do sagrado nos Sertões de Canindé constitui um apoio e uma orientação. Para Rosendahl (1996), o homem religioso sente necessidade de viver numa atmosfera do sagrado e de construir ritualmente o espaço sagrado. Chegar à Canindé, é cumprir um ato de voluntariedade, onde cada romeiro decide quando fazer sua caminhada e qual forma vai cumprir sua promessa. Cavalcante (1998), nos explica que no caso de Canindé, desde que a pessoa resolve fazer a romaria, é comum usar uma indumentária e submeter-se a todo um 
aprendizado de iniciação o que o tornaria apto a partir. Nesse momento ocorre a irrupção do indivíduo com o cotidiano, passando-se a viver o mais possível no sagrado ou muito perto dos objetos sagrados (ELIADE, 1996).

Sendo o sertão cearense marcado pela seca e palco de motivações religiosas, entre as quais destacam-se os rituais solicitando chuva, as ideias de milagres e providências acabam opondo à ordem da natureza, onde o homem irá se valer da religião para melhorar sua vida, que se delinearia conforme a definição de Dardel citada por Holzer (1999), na essência da paisagem representada por um conjunto, uma convergência, um momento vivido.

Essa teia de significados que compõem a paisagem sagrada em Canindé é marcada por elementos a serem considerados: santuário, capelas, altares, utensílios e também pelos gestos representados pelo silêncio, o olhar, as orações, os cânticos, o sofrimento, as celebrações, festas, etc, que torna estes atos ou gestos sagrados possuidores de uma conotação religiosa e que se vincula a determinados aspectos da paisagem, tornando-a fundamental enquanto símbolo ou horizontes para sua vida. Aqui a paisagem que está associada ao sagrado, é construída numa tentativa de dar sentido à própria existência. A construção de um universo simbólico vem garantir a satisfação de necessidades básicas que não podem ser satisfeitas de outra maneira.

A interpretação da romaria na paisagem dos Sertões de Canindé é entendida como um ato que ultrapassa a necessidade de dominar as adversidades da natureza, mas também a necessidade de dominar o meio sobrenatural e social. Esse é o sen- timento que reveste o homem religioso. Segundo Durkheim (1996), não deverá haver nenhuma irracionalidade nesse ato, onde o sobrenatural não se reduz de modo algum ao imprevisto.

Além da prática da romaria, que empresta ao lugar um elevado valor simbólico, podemos observar que outros elementos significativos somamse a essa paisagem, aqui representados pela presença das cruzes e marcos obituários localizados ao longo da rodovia que liga a cidade de Canindé à Fortaleza. Trata-se de elementos simbólicos que refletem e que, forjam uma identidade e no dizer de Bonnemaison (2000), podem ser entendidos como geossímbolos, pois assinalam o território através de sua dimensão simbólica, conferindo também uma territorialidade cultural.

Dessa forma, a presença das cruzes e dos marcos obituários na estrada de Canindé está associada a ícones que formatam uma paisagem imbuída de significados e que segundo Hartig e Dunn (1998), representam elementos de uma paisagem sagrada porque comemoram a morte e determinam uma certa reverência a uma vida nômade. A simbiose existente entre esses geossímbolos e o sujeito nos permite elencar algumas reflexões no sentido de compreender como a paisagem cultural aí é construída. A dimensão gestual, os diversos olhares, a solidariedade grupal, entre outros, contribuem para a compreensão através dos símbolos de um processo que se expressa por meio de imagem e metáforas da paisagem, estabelecendo assim um código mágico-religioso nas relações de analogia ou similaridade entre o símbolo e aquilo que substitui e representa.

Considerados como artefatos provenientes de uma hibridação étnica e religiosa, ou seja, uma 
combinação da tradição católica européia com os costumes indígenas (HENZEL, 1989), os marcos obituários são considerados sagrados, pois sugerem uma manifestação simbólica para reverenciar uma vida passada, representando portanto uma linguagem essencialmente simbólica que, embora implícita, possui elementos que se articulam com a realidade, dando um sentido aos fenômenos que verifica nos acontecimentos que vive, estabelecendo relações entre o mundo real e o sobrenatural.

A presença das cruzes às margens da estrada de Canindé ajudam a compor a sacralidade daquela paisagem, exercendo uma função simbólica que permite ao romeiro ou ao transeunte ir além da aparência natural do símbolo sagrado, porém impregnando-o de um significado especial que é elaborado graças à construção de uma linguagem que estabelece com o sagrado. $\mathrm{Na}$ tentativa de conjugar elementos geossimbólicos dentro de uma contextualidade de um espaço sagrado, explica Rosendahl (1996) que o homem se exprime sob formas simbólicas que se relacionam no espaço, sendo as formas e os objetos de culto eivados de uma aura de elevado valor moral

\section{NOTAS}

1. Universidade Estadual do Ceará. Laboratório de Estudos Urbanos e Geografia Cultural

\section{BIBLIOGRAFIA}

ALENCAR, José de. O Sertanejo. Fortaleza: Diário do Nordeste, 2001

ALVES JÙNIOR, Nilo. Turismo religioso: caminhos da fé. Fortaleza, SENAC/SEBRAE, 2003.

ALMEIDA, Maria Geralda de. Em busca do poético dos sertões: um estudo de representações. In: ALMEIDA, M. G de e RATTS, A. J. P. (Orgs.) Geografia: leituras culturais. Goiânia: Ed. Alternativa, 2003.

BACHELARD, Gaston. A poética do Espaço. São Paulo: Martims Fontes, 1993

BOMER, Bernard. Lê paysage vu par les geographes et par les autres. Paris: Bull.Assoc. Geogr. Française, 1994.
BONNEMAISON, Joel. La geograpbie culturel. Paris: Editions du CTHS, 2000

BOURDIEU, Pierre. O poder simbólico. Rio de Janeiro: Bertrand Brasil, 1990

BUTTIMER, Anne. Aprendendo o dinamismo do mundo vivido. In: CHRISTOFOLETTI, A. (Org.) Perspectiva da Geografia. São Paulo: DIFEL, 1985.

COSGROVE, Denis. Mundos dos significados: geografia cultural e imaginação. In: CORREA, R. L. e ROSENDHAL Z. (Orgs) Geografia Cultural: um século (2). Rio de Janeiro: EdUERJ, 2000

COSGROVE, Denis; Jackson. P. Novos rumos da geografia cultural. In: CORREA, R. L. e ROSENDHAL, Z. (Orgs) Introdução à Geodrafia Cultural. Rio de Janeiro: Bertrand Brasil, 2003.

CLAVAL, P. Etnogeografias. In: Espaço e Cultura. UERJ, Rio de Janeiro, $\mathrm{n}^{\circ} 7$ jan./jun. de 1999

CASTRO, Iná Elias de. Mito da necessidade. Discurso e prática do regionalismo nordestino. Rio de Janeiro: Bertrand Brasil, 1992.

DURKHEIM, Emile. As formas elementares da vida religiosa. São Paulo: Martins Fontes, 1996.

ELIADE, Mircea. Imagens e símbolos: ensaio sobre o simbolismo mágico- religioso. São Paulo: Martins Fontes, 1991.

Mircea. O sagrado e o profano: a essência das religiões. São Paulo: Martins Fontes, 1996

FERREIRA, A. L. de A.; DANTAS, G. A. F. Os indesejáveis na cidade: as representações do retirante da seca. (Natal, 1890-1930), Scripta Nova: Rev. Electronica de Geografia y Ciências Sociales. Barcelona. Universidad de Barcelona, nº 94 - ago, 2001.

GEERTZ, Clifford. A interpretação das culturas. Rio de janeiro: LTC - Livro Técnico e Científico Editora, 1989

GIL FILHO, Sylvio Fausto. Geografia Cultural: estrutura e primado das representações. Espaço e Cultura. UERJ, Rio de Janeiro, no 19-20, p. 61-70. jan/dez 2005.

HARTIG, Kate V. e DUNN, Kevin. Roadsides Memorials: interpreting news deathscapes in Newcastle, New South Wales. Australian Geographical Studies. 36 (1): 5-20, March, 1998.

HENZEL, C. Cruces in the roadsides landscape of northeastern. México Journal of Cultural Geography, 11. 93-106, 1989

HOEFLE, Scott William. Visões do outro mundo e desencantamento ambiental e social no sertão nordestino. Espaço e Cultura, no 2 (junho / 1996). Rio de Janeiro: NEPEC,1996

HOLZER, Werther. A geografia fenomenológica de Eric Dardel. In: CORREA, R L. e ROSENDHAL, Z. (orgs). Matrizes da Geografia Cultural. Rio de Janeiro: EDUERJ, 2001

Werther. Paisagem, imaginário, identidade: alternativas para o estudo geográfico. In: CORREA, R L. e ROSENDHAL, Z. (orgs). Manifestações da Cultura no Espaço. Rio de Janeiro: EDUERJ, 1999

MONET, Jérome. Semiologia de los espacios políticos em la ciudad de México. In: DELGADO, J. (org.) Câmbios territoriales em México. México-DF: UAM- Xochimilco, 1991

PEIRCE, Charles S. Semiótica. São Paulo: Editora Perspectiva, 1990

PORDEUS JUNIOR, Ismael. Cearensidade. In: CARVALHO, Gilmar de (org.) Bonito pra chover. Fortaleza: Ed. Demócrito Rocha, 2003

RAPOPORT, A. The meaning of the built environment. Londres: Sage, 1982 
ROSENDAHL, Zeny. Espaço e religião: uma abordagem geográfica. Rio de Janeiro: EDUERJ, 1996

SILVA, Cícero Nilton M. Religiosidade e Política: a construção da espacialidade da romaria da terra no Estado do Ceará. Dissertação de Mestrado. Curso de Mestrado em Geografia da Universidade Estadual do Ceará, 2003
SILVA, Maria Joseli. Cultura e territorialidade urbana: uma abordagem da pequena cidade. Revista de História Regional. Vol. $5-\mathrm{n}^{\circ} 2,2000$

SOUZA, Candice Vidal. A pátria geográfica: sertão e litoral no pensamento social brasileiro. Goiânia: Ed. UFG, 1997.

\section{ABSTRACT}

THE CONNECTIONS BETWEEN LANDSCAPE AND SYMBOLS ARE ROOTED IN THEORETICAL SOURCES OF CULTURAL GEOGRAPHY, SEARCHING TO EXPLAIN THE EXISTENCE OF A WHOLE OF SIGNS THAT MOULD LANDSCAPES. THE AIM OF THIS TEXT IS TO MAKE SOME REFLECTIONS ABOUt CULtURAL landSCAPE OF SERTÕES DE CANINDÉ.(STATE OF (EARÁ) AND tO PERCEIVE ITS SYMBOLIC ASPECT. IN THE CONTEXT OF SACRED PERSPECTIVE, IS IDENTIFIED TWO TYPICAL COMPONENTS:

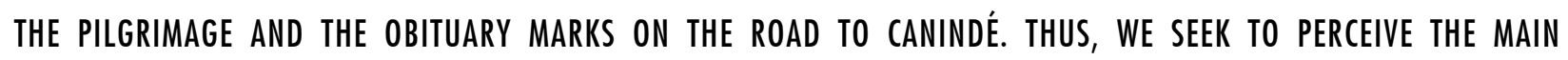
GEOSYMBOLIC ELEMENTS, IN ORDER TO UNDERSTANDING THAT THE LANDSCAPE SHOWS US SUCH CULTURE AND ACCOMPLISHES A ROLE OF CULTURAL TRANSFORMATION WHICH REPRESENTATION ARE SYMBOLIC FORMS THAT PRODUCE PLURAL MEANINGS.

KEYWORDS: GEOSYMBOL - LANDSCAPE -- SACRED - SERTÃO 